Article

\title{
Obesity May Not Be Associated with 28-Day Mortality, Duration of Invasive Mechanical Ventilation and Length of Intensive Care Unit and Hospital Stay in Critically Ill Patients with Severe Acute Respiratory Syndrome Coronavirus-2: A Retrospective Cohort Study
}

\author{
Sjaak Pouwels*(D), Dharmanand Ramnarain, Emily Aupers, Laura Rutjes-Weurding and Jos van Oers $\mathbb{D}$ \\ Department of Intensive Care Medicine, Elisabeth-Tweesteden Hospital, Hilvarenbeekseweg 60, \\ P.O. Box 90151, 5000 LC Tilburg, The Netherlands; d.ramnarain@etz.nl (D.R.); e.aupers@etz.nl (E.A.); \\ l.weurding@gmail.com (L.R.-W.); jah.vanoers@etz.nl (J.v.O.) \\ * Correspondence: Sjaakpwls@gmail.com
}

check for updates

Citation: Pouwels, S.; Ramnarain, D.; Aupers, E.; Rutjes-Weurding, L.; van Oers, J. Obesity May Not Be Associated with 28-Day Mortality, Duration of Invasive Mechanical Ventilation and Length of Intensive Care Unit and Hospital Stay in Critically Ill Patients with Severe Acute Respiratory Syndrome Coronavirus-2: A Retrospective Cohort Study. Medicina 2021, 57, 674. https://doi.org/10.3390/ medicina57070674

Academic Editors:

Edgaras Stankevičius and Gudrun Kunst

Received: 25 May 2021

Accepted: 28 June 2021

Published: 29 June 2021

Publisher's Note: MDPI stays neutral with regard to jurisdictional claims in published maps and institutional affiliations.

Copyright: (c) 2021 by the authors. Licensee MDPI, Basel, Switzerland. This article is an open access article distributed under the terms and conditions of the Creative Commons Attribution (CC BY) license (https:// creativecommons.org/licenses/by/ $4.0 /)$.
Abstract: Background and Objectives: The aim of this study was to investigate the association between obesity and 28-day mortality, duration of invasive mechanical ventilation and length of stay at the Intensive Care Unit (ICU) and hospital in patients admitted to the ICU for SARS-CoV-2 pneumonia. Materials and Methods: This was a retrospective observational cohort study in patients admitted to the ICU for SARS-CoV-2 pneumonia, in a single Dutch center. The association between obesity (body mass index $>30 \mathrm{~kg} / \mathrm{m}^{2}$ ) and 28-day mortality, duration of invasive mechanical ventilation and length of ICU and hospital stay was investigated. Results: In 121 critically ill patients, pneumonia due to SARS-CoV-2 was confirmed by RT-PCR. Forty-eight patients had obesity (33.5\%). The 28-day all-cause mortality was $28.1 \%$. Patients with obesity had no significant difference in 28 -day survival in Kaplan-Meier curves (log rank $p$ 0.545) compared with patients without obesity. Obesity made no significant contribution in a multivariate Cox regression model for prediction of 28-day mortality $(p=0.124)$, but age and the Sequential Organ Failure Assessment (SOFA) score were significant independent factors $(p<0.001$ and 0.002 , respectively). No statistically significant correlation was observed between obesity and duration of invasive mechanical ventilation and length of ICU and hospital stay. Conclusion: One-third of the patients admitted to the ICU for SARS-CoV-2 pneumonia had obesity. The present study showed no relationship between obesity and 28-day mortality, duration of invasive mechanical ventilation, ICU and hospital length of stay. Further studies are needed to substantiate these findings.

Keywords: severe acute respiratory syndrome coronavirus-2; SARS-CoV-2; obesity; length of stay; intensive care unit; invasive mechanical ventilation

\section{Introduction}

In December 2019, the first patients suffered from an unknown disease-entity causing pneumonia-like symptoms. Later on, weeks after the first deaths, the novel strain of a virus, severe acute respiratory syndrome coronavirus-2 (SARS-CoV-2), was identified. SARSCoV-2 spread rapidly across the globe causing major health catastrophes and widespread panic, social unrest and economic instability of which the long-term consequences are yet to be determined [1-3]. Unfortunately, to date, the rate of newly diagnosed patients is still rising, [1] In several papers, there seem to be different factors that might be associated with an increased risk of hospitalization and mortality in patients with SARS-CoV-2. Among them are advanced age (>60 years), obesity (body mass index (BMI) $>30 \mathrm{~kg} / \mathrm{m}^{2}$ ), diabetes, hypertension, cardiovascular disease, as well as a history of smoking and chronic obstructive pulmonary disease (COPD) [1-6]. In several clinical reports, obesity was 
determined as an independent risk factor for SARS-CoV-2 increased severity of the disease and death [7-10]. In a recent study conducted by Simonnet et al. [10], there was a high prevalence of obesity among patients with SARS-CoV-2 requiring invasive mechanical ventilation. Moreover, severe obesity (defined as $(\mathrm{BMI})>35 \mathrm{~kg} / \mathrm{m}^{2}$ ) was significantly associated with the need for invasive mechanical ventilation [10]. Similar results were found in the clinical report of Caussy et al. [11]. However, there is currently no evidence of the effects of overweight and obesity on the duration of invasive mechanical ventilation, hospital and/or intensive care unit (ICU) stay and 28-day mortality.

The primary aim of the present study was to investigate the association between obesity and 28-day mortality. Secondly, the association between obesity and duration of invasive mechanical ventilation and length of stay (LOS) at the ICU and hospital in patients admitted to the ICU for SARS-CoV-2 was investigated.

\section{Materials and Methods}

\subsection{Study Design and Patient Enrolment}

In this single-center retrospective observational cohort study, we enrolled all patients that were admitted to the ICU for SARS-CoV-2 pneumonia in the Elisabeth-Tweesteden Hospital in Tilburg in the Netherlands between 2 March and 5 June 2020. Patients were diagnosed according to the criteria that were set up by the World Health Organization interim guidance [1,2]. Patients were suspected of a SARS-CoV-2 pneumonia if one or more of the following symptoms were present (on either a conventional chest X-ray or a computed tomography (CT) scan) and one or more of the following symptoms were present: dyspnea, increased respiratory insufficiency, decreased blood oxygen saturation and the need for supportive oxygen therapy $[1,2]$. Throat swab samples were obtained from all patients at admission and were tested using a real-time reverse transcriptase-polymerase chain reaction assay (RT-PCR) to identify a SARS-CoV-2 infection [1,2]. In case of a high suspicion based on clinical judgement or computed tomography (CT) scan and multiple negative tests, deep bronchial aspirates and feces tests were performed to determine the diagnosis $[1,2]$. Patients with a pneumonia were excluded if no SARS-CoV-2 could be detected by PCR or if SARS-CoV-2 pneumonia was present.

This study was performed in accordance with the ethical standards as laid down in the 1964 Declaration of Helsinki and was conducted according to the Strengthening the Reporting of Observational studies in Epidemiology (STROBE) statement [3]. The Medical Ethical Committee of Elisabeth-Tweesteden hospital in Tilburg, the Netherlands, approved this study and waived the need for informed consent (protocol number: L0977.2020).

\subsection{Outcomes}

The primary outcome of this study was 28-day mortality in critically ill patients with SARS-CoV-2. Secondary outcomes were the length of hospital stay, length of ICU stay and the duration of invasive mechanical ventilation. Length of hospital stay and length of ICU stay were defined as the total duration of hospital or ICU admittance for a SARS-CoV-2 infection, counting the ventilator days, which are the total number of days that patients were on a mechanical ventilator, assessed the duration of invasive mechanical ventilation. The following patient characteristics were analyzed: gender, age, height, length, BMI, and the presence of comorbidities.

\subsection{Data Collection and Statistical Analysis}

Clinical data and microbiological and laboratory results were prospectively collected on a daily basis in patients enrolled in the study. Three trained physicians (S.P., D.R., J.v.O.) collected and reviewed the epidemiological data, past medical history, treatments, clinical data and outcomes for all consecutive patients from their admission to 5 June 2020.

Because of the retrospective and exploratory nature of this study, no formal sample size and power calculation was done. All non-normally distributed data (KolmogorovSmirnov test $p<0.05$ ) are expressed as median (with interquartile range, IQR) or as number 
of patients (percentage) where appropriate. Patient characteristics and outcomes were compared using a Mann-Whitney $U$ test for continuous variables and chi-square test for categorical variables. The cumulative survival was analyzed by applying the Kaplan-Meier curves, and differences in mortality were compared with the log rank test. Univariate and multivariate Cox regression proportional hazards regression analyses were conducted to study the effects on 28-day mortality. The relation between obesity and duration of invasive mechanical ventilation, LOS ICU and hospital was analyzed by correlation analysis. All tests were two-sided and a $p$-value $<0.05$ was considered statistically significant. All data were analyzed using a statistical software package (SPSS Inc., version 24, Chicago, IL, USA)

\section{Results}

\subsection{Descriptive Characteristics of the Patients}

A total of 143 patients were admitted to the ICU with a suspected SARS-CoV-2 pneumonia during the study period. In 121 patients with pneumonia, SARS-CoV-2 was confirmed by RT-PCR. The patient flow diagram shows the flow of patients along with the primary endpoint of 28-day survival (Figure 1).

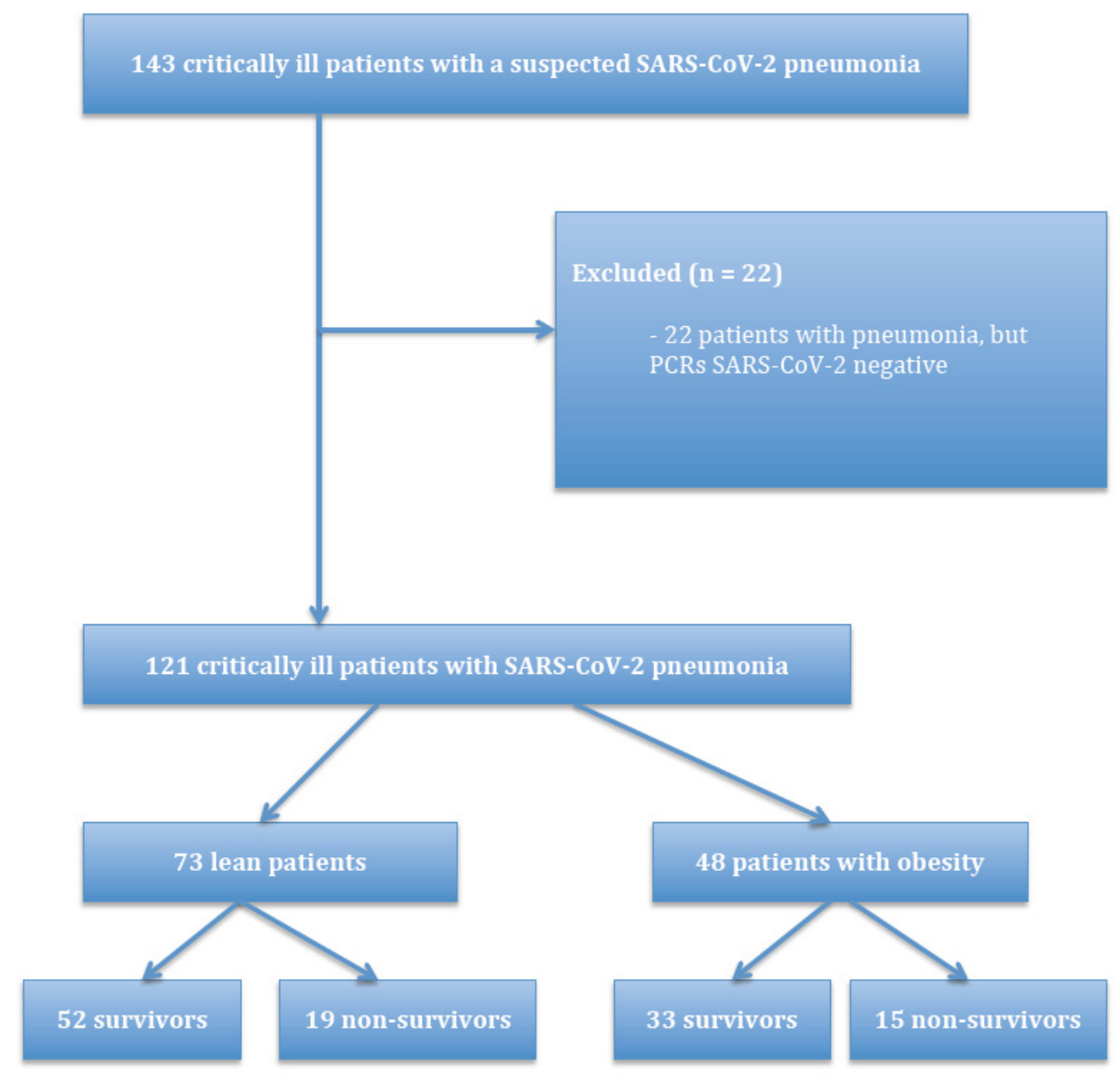

Figure 1. Patient inclusion flow diagram.

Demographics and clinical characteristics of the 121 selected patients are shown in Table 1. A total of 116 patients were septic, and 12 patients were in septic shock, according to the Sepsis-3 definitions. The 28-day all-cause mortality was $28.1 \%$. Median duration of invasive mechanical ventilation was 14 days, and ICU and hospital LOS were 16 and 20 days, respectively. Patients were divided in two groups: patients with and without obesity. Forty-eight patients had obesity (33.5\%). Both groups were comparable except for older age in the group of patients without obesity. There were also no significant differences in inflammatory biomarkers, white blood count (WBC) and C-reactive protein (CRP) between patients with and without obesity. 
Table 1. Clinical characteristics of patients with COVID-19 pneumonia at baseline with regard to body mass index.

\begin{tabular}{|c|c|c|c|c|}
\hline & Total & $\begin{array}{c}\text { Non-Obese } \\
\left(\mathrm{BMI} \leq 30 \mathrm{~kg} / \mathrm{m}^{2}\right)\end{array}$ & $\begin{array}{c}\text { Obese } \\
\left(\mathrm{BMI}>30 \mathrm{~kg} / \mathrm{m}^{2}\right)\end{array}$ & $p$ Value \\
\hline & $(n=121)$ & $(n=73)$ & $(n=48)$ & \\
\hline Age (years) (median, IQR) & $68(60-74)$ & $71(63-75)$ & $65(56-71)$ & 0.003 \\
\hline Male gender $(\mathrm{N}, \%)$ & $91(75.2 \%)$ & $58(79.5 \%)$ & $33(68.8 \%)$ & 0.182 \\
\hline \multicolumn{5}{|l|}{ Pre-existing comorbidities $(\mathrm{N}, \%)$} \\
\hline Hypertension & $37(30.6 \%)$ & $21(28 \%)$ & $16(33.3 \%)$ & 0.594 \\
\hline Congestive heart failure & $23(19 \%)$ & $11(15.1 \%)$ & $12(25 \%)$ & 0.173 \\
\hline COPD & $20(16.5 \%)$ & $10(13.7 \%)$ & $10(20.8 \%)$ & 0.301 \\
\hline Diabetes mellitus & $31(25.6 \%)$ & $16(21.9 \%)$ & $15(31.3 \%)$ & 0.250 \\
\hline Cerebrovascular disease & $6(5 \%)$ & $4(5.5 \%)$ & $2(4.2 \%)$ & 0.745 \\
\hline Malignancy & $18(14.9 \%)$ & $11(15.1 \%)$ & $7(14.6 \%)$ & 0.942 \\
\hline Chronic renal disease & $6(5 \%)$ & $2(2.7 \%)$ & $4(8.3 \%)$ & 0.166 \\
\hline Auto-immune disorder & $9(7.4 \%)$ & $7(9.6 \%)$ & $2(4.2 \%)$ & 0.266 \\
\hline \multicolumn{5}{|l|}{ Severity of illness } \\
\hline Sepsis-3, sepsis (N, \%) & $116(95.9 \%)$ & $71(97.3 \%)$ & $45(93.8 \%)$ & 0.343 \\
\hline Sepsis-3, septic shock (N, \%) & $12(9.9 \%)$ & $6(8.2 \%)$ & $6(12.5 \%)$ & 0.441 \\
\hline SOFA score (points) (median, IQR) & $5(3-7)$ & $6(3-7)$ & $5(3-7)$ & 0.504 \\
\hline \multicolumn{5}{|l|}{ Inflammatory biomarkers } \\
\hline WBC, 10E9/L, (median, IQR) & $8.3(6.1-11.8)$ & $8.4(6.4-12.2)$ & $7.6(5.4-11.2)$ & 0.317 \\
\hline CRP (mg/L), (mean, sd) & $141(90-205)$ & $138(90-221)$ & $149(87-185)$ & 0.592 \\
\hline \multicolumn{5}{|l|}{ Treatment during ICU stay (N, \%) } \\
\hline High flow nasal cannula & $10(8.3 \%)$ & $6(8.2 \%)$ & $4(8.3 \%)$ & 0.982 \\
\hline Invasive mechanical ventilation & $111(91.7 \%)$ & $67(91.8 \%)$ & $44(91.7 \%)$ & 0.982 \\
\hline Prone position ventilation & $65(53.7 \%)$ & $37(50.7 \%)$ & $28(53.8 \%)$ & 0.409 \\
\hline Corticosteroids (methylprednisolone) & $5(4.1 \%)$ & $1(1.4 \%)$ & $4(8.3 \%)$ & 0.060 \\
\hline Vasopressors & $99(81.8 \%)$ & $61(83.6 \%)$ & $38(79.2 \%)$ & 0.540 \\
\hline Renal replacement therapy & $9(7.4 \%)$ & $3(4.1 \%)$ & $6(12.5 \%)$ & 0.085 \\
\hline \multicolumn{5}{|l|}{ Anti-COVID-19 therapy } \\
\hline Chloroquine only & $84(69.4 \%)$ & $54(74 \%)$ & $30(62.5 \%)$ & 0.180 \\
\hline Chloroquine + lopinavir/ritonavir & $36(29.8 \%)$ & $18(24.7 \%)$ & $18(37.5 \%)$ & 0.131 \\
\hline IL 1 antagonist & $2(1.7 \%)$ & $0(0 \%)$ & $2(4.2 \%)$ & 0.079 \\
\hline \multicolumn{5}{|l|}{ Outcome } \\
\hline Ventilation in days (median, IQR) & $14(8-23)$ & $14(7-23)$ & $12(8-17)$ & 0.945 \\
\hline ICU LOS (days) (median, IQR) & $16(9-31)$ & $18(9-29)$ & $14(9-17)$ & 0.621 \\
\hline Hospital LOS (days) (median, IQR) & $20(12-30)$ & $23(12-33)$ & $17(10-27)$ & 0.252 \\
\hline 28-day mortality (N, \%) & $34(28.1 \%)$ & $19(26 \%)$ & $15(31.3 \%)$ & 0.532 \\
\hline
\end{tabular}

Legend: All continuous data are presented as median (interquartile range) and categorical data as number (percentage). Abbreviations: COPD: chronic obstructive pulmonary disease, SOFA: Sequential Organ Failure Assessment, WBC: white blood count, CRP: C-reactive protein, IL 1 antagonist: interleukin 1 antagonist, ICU LOS: length of stay in the intensive care unit. Bold values: statistically significant $p$ value $<0.05$. 


\subsection{Association between Obesity and 28-Day Mortality}

All-cause 28 -day mortality in all patients was $28.1 \%$. There were no significant differences in 28-day mortality between patients with and without obesity ( $p=0.545)$ (Figure 2). Obesity made no significant contribution in univariate and multivariate Cox regression analysis for prediction of 28-day mortality (Table 2). Age (HR $1.11(1.05-1.17), p<0.001)$ and SOFA (Sequential Organ Failure Assessment) score (HR 1.37 (1.12-1.67), $p=0.002$ ) were significant independent factors in a multivariate model for prediction of 28-day mortality. Tables 3 and 4 show univariate and multivariate analyses for males and females separately. In males (Table 3), both SOFA score (HR $1.36(1.08-1.73), p=0.01)$ and age (HR $1.12(1.05-1.20), p=0.001)$ remain significant independent factors for prediction of 28-day mortality, whereas in females both are not significant.

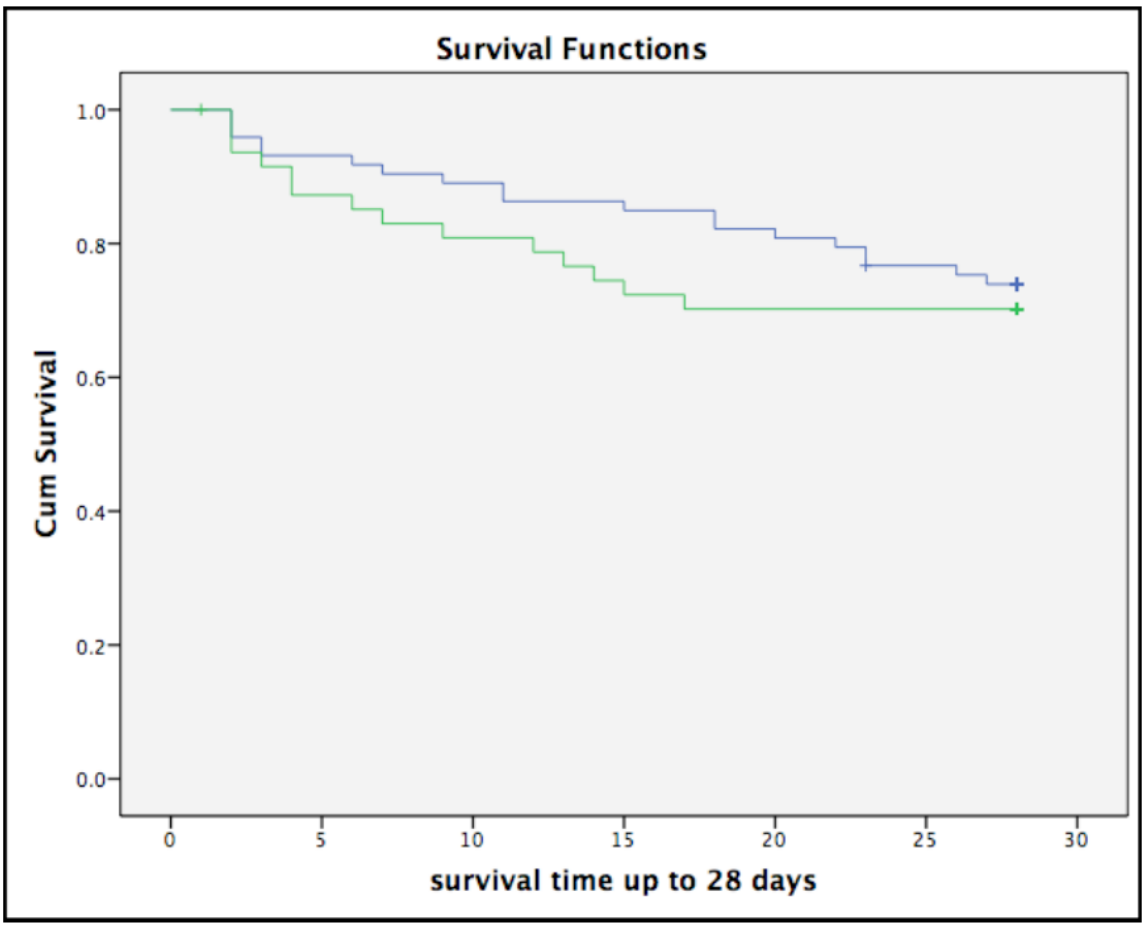

Figure 2. Kaplan-Meier curve 28-day survival. Legend: Blue line: $\mathrm{BMI} \leq 30 \mathrm{~kg} / \mathrm{m}^{2}$, green line: $\mathrm{BMI}>30 \mathrm{~kg} / \mathrm{m}^{2} . \log \operatorname{rank} p=0.545$.

Table 2. Univariate and multivariate Cox regression 28-day mortality.

\begin{tabular}{|c|c|c|c|c|c|c|}
\hline Variables & & & Univariate & & Multivariate & \\
\hline & Patients & Mortality & HR (95\% CI) & $p$ Value & HR (95\% CI) & $p$ Value \\
\hline Age & 121 & 34 & 1.09 (1.04-1.15) & $<0.001$ & $1.11(1.05-1.17)$ & $<0.001$ \\
\hline Male & 121 & 34 & $1.45(0.57-3.52)$ & 0.407 & $0.84(0.33-2.13)$ & 0.710 \\
\hline Diabetes & 121 & 34 & $1.17(0.54-2.51)$ & 0.697 & $0.74(0.32-1.73)$ & 0.493 \\
\hline Hypertension & 121 & 34 & $1.17(0.57-2.42)$ & 0.666 & $1.38(0.61-3.15)$ & 0.439 \\
\hline SOFA & 121 & 34 & $1.34(1.12-1.60)$ & 0.001 & $1.37(1.12-1.67)$ & 0.002 \\
\hline BMI & 121 & 34 & & & & \\
\hline$\leq 30 \mathrm{~kg} / \mathrm{m}^{2}$ & & & 1.0 (Reference) & & 1.0 (Reference) & \\
\hline$>30 \mathrm{~kg} / \mathrm{m}^{2}$ & & & $1.24(0.62-2.47)$ & 0.548 & $1.74(0.86-3.54)$ & 0.124 \\
\hline
\end{tabular}

Abbreviations: HR: hazard ratio, SOFA: Sequential Organ Failure Assessment, BMI = body mass index. Bold values: statistically significant $p$ value $<0.05$. 
Table 3. Univariate and multivariate Cox regression 28-day mortality in males.

\begin{tabular}{|c|c|c|c|c|c|c|}
\hline Variables & & & Univariate & & Multivariate & \\
\hline & Patients & Mortality & HR (95\% CI) & $p$ Value & HR (95\% CI) & $p$ Value \\
\hline Age & 91 & 27 & $1.10(1.04-1.17)$ & $<0.001$ & $1.12(1.05-1.20)$ & 0.001 \\
\hline Diabetes & 91 & 27 & $1.31(0.547-2.30)$ & 0.520 & $0.59(0.24-1.49)$ & 0.267 \\
\hline Hypertension & 91 & 27 & $1.44(0.66-3.14)$ & 0.363 & $1.70(0.73-3.99)$ & 0.222 \\
\hline SOFA & 91 & 27 & $1.33(1.08-1.63)$ & 0.007 & $1.36(1.08-1.73)$ & 0.010 \\
\hline BMI & 91 & 27 & & & & \\
\hline$\leq 30 \mathrm{~kg} / \mathrm{m}^{2}$ & & & 1.0 (Reference) & & 1.0 (Reference) & \\
\hline$>30 \mathrm{~kg} / \mathrm{m}^{2}$ & & & $1.10(0.50-2.39)$ & 0.821 & $1.50(0.66-3.41)$ & 0.337 \\
\hline
\end{tabular}

Abbreviations: HR: hazard ratio, SOFA: Sequential Organ Failure Assessment, BMI = body mass index. Bold values: statistically significant $p$ value $<0.05$.

Table 4. Univariate and multivariate Cox regression 28-day mortality in females.

\begin{tabular}{|c|c|c|c|c|c|c|}
\hline Variables & & & Univariate & & Multivariate & \\
\hline & Patients & Mortality & HR (95\% CI) & $p$ Value & HR (95\% CI) & $p$ Value \\
\hline Age & 30 & 7 & $1.01(0.95-1.09)$ & 0.756 & $1.07(0.95-1.21)$ & 0.278 \\
\hline Diabetes & 30 & 7 & $0.55(0.07-4.58)$ & 0.582 & $0.97(0.07-13.33)$ & 0.984 \\
\hline Hypertension & 30 & 7 & $0.38(0.05-3.14)$ & 0.367 & $0.38(0.03-5.35)$ & 0.476 \\
\hline SOFA & 30 & 7 & $1.42(0.99-2.02$ & 0.054 & $1.33(0.97-1.82)$ & 0.078 \\
\hline BMI & 30 & 7 & & & & \\
\hline$\leq 30 \mathrm{~kg} / \mathrm{m}^{2}$ & & & 1.0 (Reference) & & 1.0 (Reference) & \\
\hline$>30 \mathrm{~kg} / \mathrm{m}^{2}$ & & & $\begin{array}{c}2.93 \\
(0.57-15.11)\end{array}$ & 0.200 & $4.99(0.65-38.06)$ & 0.121 \\
\hline
\end{tabular}

Abbreviations: HR: hazard ratio, SOFA: Sequential Organ Failure Assessment, BMI = body mass index.

\subsection{Association between Obesity and Duration Mechanical Ventilation, LOS ICU and Hospital}

No statistically significant correlation was observed between BMI and number of days on the ventilator (Spearman's rho 0.009, $p=0.925$ ). No significant correlation between BMI and number of ICU days (Spearman's rho $-0.053, p=0.563$ ) and no significant correlation between BMI and number of days in hospital (Spearman's rho $-0.093, p=0.328$ ) were found/observed.

\section{Discussion}

The primary aim of our study was to investigate the association between obesity and 28-day mortality. Secondary outcomes were the association between obesity and duration of invasive mechanical ventilation, length of stay (LOS) at the ICU and hospital in patients admitted to the ICU for SARS-CoV-2. In our study we found no relationship between obesity and 28-day mortality in a cohort of patients admitted at the ICU department for SARS-CoV-2. Additionally, in our study there was no relationship between obesity and ICU length of stay, hospital length of stay and ventilator days. Only age and SOFA were significant independent factors associated with 28-day mortality.

Worldwide changes in lifestyle, consumer markets and urbanization are important causes of the obesity pandemic. Since 1975, obesity incidence and prevalence numbers have been rising significantly, according to the World Health Organization (WHO) [4-6].

To date it has been estimated that approximately 1.9 billion adults are overweight, and secondly, there are approximately 650 million people with obesity [5,6]. Comparing these numbers with the 1970 s, it indicates a rise of $300 \%[5,6]$. Of course we also have to take into account that the world population also grows, but still there is a global prevalence of 
obesity of $37 \%$ compared with $27 \%$ back in the 1970 s [5,6]. It is no surprise that the obesity pandemic has a high impact on health care providers globally, and with the SARS-CoV-2 pandemic, it has been put into a "new" perspective $[5,6]$. In general, patients with obesity have an increased risk of developing type 2 diabetes mellitus (T2DM), obstructive sleep apnea syndrome (OSAS) and numerous of cardiovascular related diseases [4,7-9].

Recently both Simonnet et al. [10] and Caussy et al. [11] showed that there is a high prevalence of patients with obesity and severe obesity in patients with SARS-CoV-2 who are in need of invasive mechanical ventilation. Both studies were performed in France and showed a different distribution in SARS-CoV-2 patients among different BMI categories. Caussy et al. [11] pointed out that in their study there was a lower prevalence of patients with a BMI $\geq 35 \mathrm{~kg} / \mathrm{m}^{2}$ than in the study done by Simonnet et al. [10] (respectively, $11.3 \%$ and $28.2 \%$ ). Same goes for the need for invasive mechanical ventilation (Caussy et al. [11] $58.4 \%$ compared with $68.6 \%$ in the study of Simonnet et al. [10]). This might be due to a difference in the prevalence of obesity in several regions and also due to the kind of strategy that is used in the treatment of these SARS-CoV-2 patients, e.g., very fast intubation or a more conservative treatment schedule [11]. It also needs to be mentioned that both studies were done in patients in the general ward. In our study, we only included ICU patients.

In the study by Caussy et al. [11], there was a higher use of high-flow oxygen therapy through a nasal cannula such as OptiflowTM (56\%). In the study by Simonnet et al. [10], this was not reported. Our own study consisted of 10 patients $(8.3 \%)$ that needed high nasal flow oxygen therapy. Recent studies done by Gupta et al. [12] and Ebinger et al. [13] indicated that obesity is associated with SARS-CoV-2 and even with increased mortality according to Gupta et al. The study by Czernichow et al. [14] showed that mortality doubles among different classes of obesity. In this study, almost 6000 patients were included, and mortality was significantly increased in people with obesity with the following OR in BMI 30-35, $35-40$ and $>40 \mathrm{~kg} / \mathrm{m}^{2}: 1.89$ (95\%CI 1.45-2.47), 2.79 (1.95-3.97) and 2.55 (1.62-3.95). Similar results were found in the study by AbdelMassih. [15] There is also a higher non-respiratory complication rate in patients with obesity, in particular, renal failure and shock [16]. Here it has to be taken into account that the studies by Czernichow et al. [14] and AbdelMassih [15] were done in a population on the general ward, and both studies were not specific for the ICU population.

With the SARS-CoV-2 pandemic and the identification of obesity as potential risk factor according to several reports [10-13], we are basically handling a "double edged sword". In the study of Caussy et al. [11], the authors state that patients with obesity might have an increasing disease severity; however, no severity score was used to assess the matter. Regarding the pathophysiology, there might be an association between SARS-CoV-2 and obesity; however, the potential mechanisms are not yet understood. In the past, obesity has been described as an independent predisposition factor for H1N1 pulmonary infection [17]. Abdominal obesity is known to possibly significantly impair ventilation in the lower parts of the lungs, resulting in reduced oxygen saturation [18]. Furthermore, it needs to be stated that inflammation is closely associated with obesity and might impair the immune response [19]. There is an inflammatory reaction initiated when adipose tissue is expanded, which causes infiltration of immune cells [20]. Studies have shown increased levels of tumor necrosis factor-alpha (TNF- $\alpha$ ), expression of ET-1, IL-1, IL-6 and reactive oxygen species (ROS) that can be produced by adipose tissue [21]. This state of chronic low-grade inflammation can lead to a dysregulated immune response in patients with obesity and SARS-CoV-2 and can have effects on the lung parenchyma and bronchi $[19,22]$. However, in our study, inflammatory biomarkers were not significantly different between patients with and without obesity. It has to be taken into account that the pathophysiological influences of obesity and COVID-19 comprise multifactorial mechanisms, which are still not fully understood. In a comprehensive review done by Sanchis-Gomar et al. [23], it has been stated that SARS-CoV-2 binds with angiotensin-converting enzyme 2 receptors on the cell surface. These receptors are more prevalent in adipose tissue, which might indicate that patients with obesity may be more susceptible to a SARS-CoV-2 infection 
with a possibly more severe clinical course. In a lot of epidemiological studies, obesity is a significant risk factor for mortality and morbidity of a SARS-CoV-2 infection [24,25]. However it has been shown by Kooistra et al. that patients with a BMI $>30 \mathrm{~kg} / \mathrm{m}^{2}$ do not have a more severe clinical course in the ICU than patients with a BMI lower that 30 . The same is the case for their immune response. Also similar to our study results, there was no significant difference between ICU-related outcome measurements (ICU length of stay, days of mechanical ventilation and 40-day mortality) between the two BMI groups. Thus, this is a part of the "obesity paradox" that clearly needs more research to elucidate possible mechanisms [26].

\section{Limitations}

There are some limitations that need to be addressed. Firstly, this was a small retrospective single-center study in which the results are hypothesis generating but cannot be used to determine a cause-and-effect relationship between obesity and SARS-CoV-2. Secondly, selection bias needs to be taken into account since our study only investigated ICU patients with SARS-CoV-2 pneumonia. Thirdly when comparing our study with other studies in the literature (Simonnet et al. [10] and Caussy et al. [11]), the median BMI in our study was lower, which might have impacted our results. Fourthly, since this study was a small retrospective study, the cross effects between different predictors could not be determined because of our sample size. Additionally, it needs to be mentioned that this retrospective study was purely focused on the patients with COVID-19 admitted to the ICU. We investigated the effects on clinical parameters in patients with obesity and COVID-19 admitted to the ICU. This is a very small subset of the COVID-19 population. Since the small number of patients might indicate that our study is underpowered, we do have to take into account that de study by Kooistra et al. [26] substantiated our findings. They showed that only that there is no clinical difference between BMI groups in ICU admitted COVID-19 patients, but there is also no difference in cytokine and immune reaction in these patients. This is probably due to the "obesity paradox", and to further elucidate this in ICU patients with COVID-19 and obesity, larger studies are indeed needed.

\section{Conclusions}

No relation was found between obesity and 28-day mortality, ICU length of stay, hospital length of stay and ventilator days in a cohort of 121 patients admitted at the ICU department for SARS-CoV-2. Only age and the SOFA were significant independent factors associated with 28-day mortality.

Author Contributions: Conceptualization, S.P., D.R., E.A., L.R.-W., J.v.O.; methodology S.P., D.R., E.A., L.R.-W., J.v.O.; formal analysis, S.P., D.R., E.A., L.R.-W., J.v.O.; investigation, S.P., D.R., E.A., L.R.-W., J.v.O.; resources, S.P., D.R. and J.v.O.; data curation, S.P., D.R., E.A., L.R.-W., J.v.O.; writing —original draft preparation, S.P., D.R., E.A., L.R.-W., J.v.O.; writing-review and editing, S.P., D.R., E.A., L.R.-W., J.v.O.; visualization, S.P., D.R., E.A., L.R.-W., J.v.O.; supervision, D.R., J.v.O.; project administration, S.P., D.R., E.A., L.R.-W., J.v.O. All authors have read and agreed to the published version of the manuscript.

Funding: This research received no external funding.

Institutional Review Board Statement: The study was conducted according to the guidelines of the Declaration of Helsinki, and the Medical Ethical Committee of Elisabeth-Tweesteden hospital in Tilburg, the Netherlands, approved this study and waived the need for informed consent (protocol number: L0977.2020, approval date 16 April 2020).

Informed Consent Statement: Informed consent was obtained from all subjects involved in the study.

Data Availability Statement: Data available upon request.

Conflicts of Interest: The authors declare no conflict of interest. 


\section{References}

1. Huang, C.; Wang, Y.; Li, X.; Ren, L.; Zhao, J.; Hu, Y.; Li, Z.; Fan, G.; Xu, J.; Gu, X.; et al. Clinical features of patients infected with 2019 novel coronavirus in Wuhan, China. Lancet 2020, 395, 497-506. [CrossRef]

2. Sethuraman, N.; Jeremiah, S.S.; Ryo, A. Interpreting Diagnostic Tests for SARS-CoV-2. JAMA 2020, 323, 2249-2251. [CrossRef]

3. von Elm, E.; Altman, D.G.; Egger, M.; Pocock, S.J.; Gotzsche, P.C.; Vandenbroucke, J.P. The Strengthening the Reporting of Observational Studies in Epidemiology (STROBE) Statement: Guidelines for reporting observational studies. Int. J. Surg. 2014, 12, 1495-1499. [CrossRef]

4. Sanches, E.; Timmermans, M.; Topal, B.; Celik, A.; Sundbom, M.; Ribeiro, R.; Parmar, C.; Ugale, S.; Proczko, M.; Stepaniak, P.S.; et al. Cardiac remodeling in obesity and after bariatric and metabolic surgery; is there a role for gastrointestinal hormones? Expert Rev. Cardiovasc. Ther. 2019, 17, 771-790. [CrossRef]

5. Ng, M.; Fleming, T.; Robinson, M.; Thomson, B.; Graetz, N.; Margono, C.; Mullany, E.; Biryukov, S.; Abbafati, C.; Abera, S.F.; et al. Global, regional, and national prevalence of overweight and obesity in children and adults during 1980-2013, a systematic analysis for the Global Burden of Disease Study 2013. Lancet 2014, 384, 766-781. [CrossRef]

6. Sjostrom, L.; Narbro, K.; Sjostrom, C.D.; Karason, K.; Larsson, B.; Wedel, H.; Lystig, T.; Sullivan, M.; Bouchard, C.; Carlsson, B.; et al. Effects of bariatric surgery on mortality in Swedish obese subjects. N. Engl. J. Med. 2007, 357, 741-752. [CrossRef]

7. Appachi, S.; Kelly, K.R.; Schauer, P.R.; Kirwan, J.P.; Hazen, S.; Gupta, M.; Kashyap, S.R. Reduced cardiovascular risk following bariatric surgeries is related to a partial recovery from "adiposopathy". Obes. Surg. 2011, 21, 1928-1936. [CrossRef] [PubMed]

8. Appachi, S.; Kashyap, S.R. 'Adiposopathy' and cardiovascular disease: The benefits of bariatric surgery. Curr. Opin. Cardiol. 2013, 28, 540-546. [CrossRef] [PubMed]

9. Lupoli, R.; Di Minno, M.N.; Guidone, C.; Cefalo, C.; Capaldo, B.; Riccardi, G.; Mingrone, G. Effects of bariatric surgery on markers of subclinical atherosclerosis and endothelial function: A meta-analysis of literature studies. Int. J. Obes. 2016, 40, 395-402. [CrossRef] [PubMed]

10. Simonnet, A.; Chetboun, M.; Poissy, J.; Raverdy, V.; Noulette, J.; Duhamel, A.; Labreuche, A.; Mathieu, D.; Pattou, F.; Jourdain, M.; et al. High prevalence of obesity in severe acute respiratory syndrome coronavirus-2 (SARS-CoV-2) requiring invasive mechanical ventilation. Obesity 2020, 28, 1195-1199. [CrossRef]

11. Caussy, C.; Wallet, F.; Laville, M.; Disse, E. Obesity is associated with severe forms of COVID-19. Obesity 2020, 28, 1175. [CrossRef] [PubMed]

12. Gupta, S.; Hayek, S.S.; Wang, W.; Chan, L.; Mathews, K.S.; Melamed, M.L.; Brenner, S.K.; Leonberg-Yoo, A.; Schenck, E.J.; Radbel, J.; et al. Factors Associated with Death in Critically Ill Patients with Coronavirus Disease 2019 in the US. JAMA Intern. Med. 2020, 180, 1436-1446. [CrossRef] [PubMed]

13. Ebinger, J.E.; Achamallah, N.; Ji, H.; Claggett, B.L.; Sun, N.; Botting, P.; Nguyen, T.-T.; Luong, E.; Kim, E.H.; Park, E.; et al. Pre-existing traits associated with Covid-19 illness severity. PLoS ONE 2020, 15, e0236240. [CrossRef]

14. Czernichow, S.; Beeker, N.; Rives-Lange, C.; Guerot, E.; Diehl, J.L.; Katsahian, S.; Hulot, J.-S.; Poghosyan, T.; Carette, C.; Jannot, A.S.; et al. Obesity doubles mortality in patients hospitalized for SARS-CoV-2 in Paris hospitals, France: A cohort study on 5795 patients. Obesity 2020, 28, 2282-2289. [CrossRef] [PubMed]

15. Fakhry AbdelMassih, A.; Ghaly, R.; Amin, A.; Gaballah, A.; Kamel, A.; Heikal, B.; Menshawey, E.; Ismail, H.-A.; Hesham, H.; Attallah, J.; et al. Obese communities among the best predictors of COVID-19-related deaths. Cardiovasc. Endocrinol. Metab. 2020, 9, 102-107. [CrossRef]

16. Onder, G.; Palmieri, L.; Vanacore, N.; Giuliano, M.; Brusaferro, S. Non-respiratory Complications and Obesity in Patients Dying with COVID-19 in Italy. Obesity 2020. [CrossRef]

17. Van Kerkhove, M.D.; Vandemaele, K.A.; Shinde, V.; Jaramillo-Gutierrez, G.; Koukounari, A.; Donnelly, C.; Carlino, L.O.; Owen, R.; Paterson, B.; Pelletier, L.; et al. Risk factors for severe outcomes following 2009 influenza A (H1N1) infection: A global pooled analysis. PLoS Med. 2011, 8, e1001053. [CrossRef]

18. Dixon, A.E.; Peters, U. The effect of obesity on lung function. Expert Rev. Respir. Med. 2018, 12, 755-767. [CrossRef]

19. Huttunen, R.; Syrjanen, J. Obesity and the risk and outcome of infection. Int. J. Obes. 2013, 37, 333-340. [CrossRef]

20. Robinson, A.T.; Fancher, I.S.; Mahmoud, A.M.; Phillips, S.A. Microvascular Vasodilator Plasticity after Acute Exercise. Exerc. Sport Sci. Rev. 2018, 46, 48-55. [CrossRef]

21. Kotsis, V.; Stabouli, S.; Papakatsika, S.; Rizos, Z.; Parati, G. Mechanisms of obesity-induced hypertension. Hypertens. Res. Off. J. Jpn. Soc. Hypertens. 2010, 33, 386-393. [CrossRef]

22. Zhang, X.; Zheng, J.; Zhang, L.; Liu, Y.; Chen, G.P.; Zhang, H.P.; Lei, W.; De, Y.K.; Wang, G.; Wood, L.G. Systemic inflammation mediates the detrimental effects of obesity on asthma control. Allergy Asthma Proc. 2018, 39, 43-50. [CrossRef] [PubMed]

23. Sanchis-Gomar, F.; Lavie, C.J.; Mehra, M.R.; Henry, B.M.; Lippi, G. Obesity and Outcomes in COVID-19, When an Epidemic and Pandemic Collide. Mayo Clin. Proc. 2020, 95, 1445-1453. [CrossRef]

24. Chu, Y.; Yang, J.; Shi, J.; Zhang, P.; Wang, X. Obesity is associated with increased severity of disease in COVID-19 pneumonia: A systematic review and meta-analysis. Eur. J. Med Res. 2020, 25, 64. [CrossRef] [PubMed]

25. Hendren, N.S.; de Lemos, J.A.; Ayers, C.; Das, S.R.; Rao, A.; Carter, S.; Rosenblatt, A.; Walchok, J.G.; Omar, W.; Khera, R.; et al. Association of Body Mass Index and Age with Morbidity and Mortality in Patients Hospitalized with COVID-19, Results from the American Heart Association COVID-19 Cardiovascular Disease Registry. Circulation 2021, 143, 135-144. [CrossRef] [PubMed]

26. Kooistra, E.J.; de Nooijer, A.H.; Claassen, W.J.; Grondman, I.; Janssen, N.A.F.; Netea, M.G.; van de Veerdonk, F.L.; van der Hoeven, J.G.; Kox, M.; Pickkers, P. A higher BMI is not associated with a different immune response and disease course in critically ill COVID-19 patients. Int. J. Obes. 2021, 45, 687-694. [CrossRef] 